\title{
Therapeutic effects of mesenchymal stem cells combined with short hairpin RNA on liver injury induced by hepatitis $B$ virus infection
}

\author{
DI LIU ${ }^{1}$, LIN LIU $^{1}$, LIZHENG WANG $^{1}$, SIZHU DUAN $^{1}$, YANAN SONG $^{1}$, MENG QU $^{1}$, NAN GAO $^{1}$, \\ JIAXIN WU ${ }^{1}$, HAIHONG ZHANG ${ }^{1}$, HUI WU ${ }^{1}$, WEI KONG ${ }^{1,2}$, BIN YU ${ }^{1}$ and XIANGHUI YU ${ }^{1,2}$ \\ ${ }^{1}$ National Engineering Laboratory for AIDS Vaccine, School of Life Sciences; ${ }^{2}$ Key Laboratory for Molecular Enzymology \\ and Engineering, The Ministry of Education, School of Life Sciences, Jilin University, Changchun, Jilin 130012, P.R. China
}

Received April 5, 2017; Accepted October 6, 2017

DOI: $10.3892 / \mathrm{mmr} .2017 .8096$

\begin{abstract}
The clinical symptoms of chronic hepatitis B virus (HBV) infection include severe liver damage, which is associated with the elimination of the HBV-infected cells by the immune system. It has been suggested that suppression of HBV replication is not sufficient for patients with hepatitis B and the damaged liver function requires restoration. In the present study, mesenchymal stem cells (MSCs) were combined with short hairpin (sh)RNA to treat liver injury and suppress HBV replication in a mouse model. Lx-shRNA157-1694 (an shRNA expression plasmid containing two shRNA expression cassettes) and mouse immortal (mi)MSCs stably expressing shRNA (miMSC-shRNA) were constructed and their suppressive effects on HBV expression were investigated using reverse transcription-polymerase chain reaction (RT-PCR), ELISA and immunofluorescence. Hepatogenic differentiation of miMSC-shRNA was induced in vitro and confirmed by morphology, reverse transcription-semi-quantitative and -quantitative PCR, urea production and Periodic acid-Schiff staining analyses. miMSCs and the shRNA expression plasmid alone or combined with miMSCs stably expressing shRNA were injected into mice. The former therapeutic regimen successfully suppressed HBV expression
\end{abstract}

Correspondence to: Dr Bin Yu or Professor Xianghui Yu, National Engineering Laboratory for AIDS Vaccine, School of Life Sciences, Jilin University, 2699 Qianjin Street, Changchun, Jilin 130012, P.R. China

E-mail: yubin@jlu.edu.cn

E-mail: xianghui@jlu.edu.cn

Abbreviations: $\mathrm{HBV}$, hepatitis B virus; MSCs, mesenchymal stem cells; shRNA, short hairpin RNA; miMSCs, mouse immortal mesenchymal stem cells; RT-qPCR, reverse transcription-quantitative polymerase chain reaction; ALT, alanine aminotransferase; AST, aspartate aminotransferase

Key words: hepatitis B virus, liver injury, mesenchymal stem cells, short hairpin RNA in sera and liver tissue, whereas the latter only suppressed HBV expression in liver tissue. Analyses of serum alanine aminotransferase levels, aspartate aminotransferase levels, liver weight/body weight ratio percentage and sirius red staining demonstrated marked amelioration of liver injury in mice treated with both therapeutic regimens. The results of the present study suggest that miMSCs combined with shRNA treatment may alleviate liver injury and suppress HBV expression, thus providing a novel potential therapeutic strategy for the treatment of liver injury induced by HBV infection.

\section{Introduction}

The World Health Organization estimates that 240 million persons globally are chronically infected with hepatitis B virus (HBV), a hepatotropic DNA virus that replicates via reverse transcription (1). HBV may induce acute and chronic infections. Chronically infected individuals are at an increased risk of liver cirrhosis and hepatocellular carcinoma (2). A critical clinical symptom of chronic hepatitis B is severe liver damage (3). As HBV is noncytopathic to infected hepatocytes, host-specific immune responses are predominantly responsible for the liver damage (4). Cytotoxic T lymphocytes (CTLs) not only clear HBV, but may also destroy infected hepatocytes (4). Furthermore, intrahepatic stellate cells are activated by the HBV infection via the stimulation of a variety of cytokines, which is followed by matrix deposition, fibrosis and eventually liver cirrhosis (3). Two types of agents are currently available for the treatment of hepatitis B: Nucleotide analogues and immune system modulator interferons (5). Nucleotide analogues may suppress viral replication but are frequently associated with an increase in drug-resistant HBV mutants, which results in treatment failure and progression to liver disease (6). Immune system modulator interferons may also suppress viral replication but the treatment is costly and side effects associated with interferons limit their clinical use (7). Although these treatments are able to suppress virus replication, they cannot relieve liver damage effectively in the long term.

Mesenchymal stem cells (MSCs) are multipotent adult stem cells present in bone marrow, adipose tissue and cord blood, 
and have been identified as an attractive candidate for liver repair (8). Various factors contribute to this promise of MSCs, including the easy isolation and expansion of these cells in culture, ability to evade the host immune response recognition, immunomodulatory properties and migratory behavior (9). MSCs have also been demonstrated to form functional hepatocytes in vitro (10) and possess the ability to secrete soluble factors stimulating endogenous parenchymal cells to support tissue recovery (11). Furthermore, MSC transplantation in a liver fibrosis model has been indicated to reduce fibrosis and restore depleted hepatic function (12).

A short hairpin (sh)RNA is an artificial RNA molecule with a tight hairpin turn that may be used to silence target gene expression via RNA interference (RNAi) (13). The pregenomic RNA, which is longer than genome length, is an essential replication intermediate that may be disabled using RNAi-based methods (14). There are four major overlapping open reading frames of the compact viral genome: PreC/core, polymerase, surface and X (15). HBV transcripts also overlap with each other and have common 3 ' sequences that are defined by the single transcription termination signal (16). Single RNAi effector molecules may therefore have cognates in more than one of the viral RNAs (17) and multiple sites on the viral genome have been successfully targeted by small interfering (si)RNAs (14).

In the present study, MSCs and shRNAs were combined to treat liver injury induced by $\mathrm{HBV}$ in a mouse model. Using in vivo and in vitro assays, it was assessed whether combined treatment may ameliorate liver injury and suppress virus replication at the same time.

\section{Materials and methods}

Cell culture. Mouse immortal mesenchymal stem cells (miMSCs; C3H10T1/2) acquired from China-Japan Union Hospital of Jilin University (Changchun, China) were cultured in Human Umbilical Cord Blood MSC Complete Medium (cat. no. HUXUB-90011; Cyagen Biosciences, Inc., Guangzhou, China). A human hepatoblastoma cell line (HepG2) and mouse hepatocellular carcinoma cell line (Hepa1-6) were purchased from the Cell Bank of the Type Culture Collection of the Chinese Academy of Sciences (Shanghai, China) and were cultured in Dulbecco's modified Eagle's medium (DMEM) supplemented with $10 \%$ fetal bovine serum (FBS) (both from HyClone; GE Healthcare Life Sciences, Logan, UT, USA). An HBV-transfected human hepatoblastoma cell line (HepG2.2.15) was purchased from Jennio Biological Technology (Guangzhou, China). HepG2.2.15 cells were cultured in DMEM supplemented with 10\% FBS. Cell cultures were performed at $37^{\circ} \mathrm{C}$ in a humidified atmosphere containing $5 \% \mathrm{CO}_{2}$.

Plasmids. Lx-shRNA157, Lx-shRNA1694 were obtained by cloning the $157 \mathrm{i}$ shRNA expression cassette and the $1694 \mathrm{i}$ shRNA expression cassette into a pLVX-shRNA1 vector (AXYBIO, Changsha, China); while LX-shRNA157-1694 was obtained by cloning both $157 \mathrm{i}$ and $1694 \mathrm{i}$ shRNA expression cassettesintoonepLVX-shRNA1 vector.Lx-shRNA157expresses 157i, which targets the HBV S gene; LX-shRNA1694 can express 1694i, which targets the HBV X gene; and LX-shRNA157-1694 has the ability to express $157 \mathrm{i}$ and $1694 \mathrm{i}$. Hygro-157-1694 contains the same RNAi target as Lx-shRNA157-1694, was constructed by Suzhou GenePharma Co., Ltd. (Suzhou, China) (http://www.genepharma.cn/index.asp). pZAC-1.2HBV, an HBV genomic expression plasmid, was obtained from Professor Panyong Mao (Beijing 302 Hospital, Beijing, China).

Evaluation of effect of transfection with Lx-shRNA157, Lx-shRNA1694 and Lx-shRNA157-1694. HepG2.2.15, a reported HBV-producing cell line (13) was used to evaluate the effect of LxshRNA157, Lx-shRNA1694 and Lx-shRNA157-1694. Three types of plasmids were transfected into HepG2.5.15 cells in 6-well-plates using Lipofectamine ${ }^{\circledR} 2000$ (Invitrogen; Thermo Fisher Scientific, Inc., Waltham, MA, USA) at $3 \mu \mathrm{g} /$ well. The transfection was done according to the manufacturer's instructions for Lipofectamine 2000. At $48 \mathrm{~h}$ post transfection, mRNA expression of HBV S and HBV X genes were detected using reverse transcription-quantitative polymerase chain reaction (RT-qPCR). The levels of HBsAg/HBeAg in the cell culture medium were also detected.

Construction of miMSCs stably expressing shRNA. The shRNA expression plasmid Hygro-157-1694 (2 $\mu \mathrm{g} /$ well in 6-well tissue culture plates) was transfected into miMSCs using Lipofectamine 2000 (Invitrogen; Thermo Fisher Scientific, Inc.). The transfection was performed according to the manufacturer's instructions for Lipofectamine 2000. At $24 \mathrm{~h}$ post-transfection, the cells were cultured with Human Umbilical Cord Blood MSC Complete Medium (cat. no. HUXUB-90011; Cyagen Biosciences, Inc.) containing hygromycin B (300 $\mu \mathrm{g} / \mathrm{ml}$; v900372; Sigma-Aldrich; Merck KGaA, Darmstadt, Germany) and $10 \%$ FBS for 14 days. The medium was removed and replaced with fresh Human Umbilical Cord Blood MSC Complete Medium containing hygromycin B $(300 \mu \mathrm{g} / \mathrm{ml})$ every 2 days. Following antibiotic selection, miMSCs stably expressing shRNA (miMSC-shRNA) were plated in Human Umbilical Cord Blood MSC Complete Medium containing hygromycin B $(50 \mu \mathrm{g} / \mathrm{ml})$ at $\sim 1$ cell/well in 96 -well tissue culture plates to select monoclones. Following culture to $1 \times 10^{6}$ cells/clone, miMSC-shRNA monoclones were stored at $-80^{\circ} \mathrm{C}$ until use. All cell culture steps were performed at $37^{\circ} \mathrm{C}$ in a humidified atmosphere containing $5 \% \mathrm{CO}_{2}$.

Evaluation of interference function of miMSC-shRNA monoclones. HBV-expressing plasmid (pZAC-1.2HBV, $3 \mu \mathrm{g}$ ) was transfected into miMSCs or two miMSCs stably expressing shRNA monoclones (miMSC-shRNA1, miMSC-shRNA2) in 6-well plates using Lipofectamine 2000 (Invitrogen; Thermo Fisher Scientific, Inc.). At $48 \mathrm{~h}$ post-transfection, HBV S and X mRNA expression levels in miMSC, miMSC-shRNA1 and miMSC-shRNA2 cells were tested using RT-qPCR. HBV preS2 antigen levels in miMSCs, miMSC-shRNA1 and miMSC-shRNA2 cells were tested by immunofluorescence.

Hepatogenic differentiation of miMSCs in vitro. Hepatogenic differentiation was performed using OriCell Human Mesenchymal Stem Cell Hepatogenic Differentiation Medium (cat. no. HUXMX-90101; Cyagen Biosciences, Inc.), which contains three types of media: Pre-treatment 
medium (containing $20 \mathrm{ng} / \mathrm{ml}$ epidermal growth factor and $10 \mathrm{ng} / \mathrm{ml}$ basic fibroblast growth factor), hepatocyte differentiation medium [containing $20 \mathrm{ng} / \mathrm{ml}$ hepatocyte growth factor (HGF), $10 \mathrm{ng} / \mathrm{ml}$ basic fibroblast growth factor and $0.61 \mathrm{~g} / \mathrm{l}$ nicotinamide] and hepatocyte maturation medium (containing $20 \mathrm{ng} / \mathrm{ml}$ oncostatin M, $1 \mu \mathrm{mol} / 1$ dexamethasone and $50 \mathrm{mg} / \mathrm{ml}$ insulin-transferrin-selenium premix). Three steps, including pretreatment, differentiation and maturation, were needed in this experiment. In pretreatment step, miMSCs were plated in Human Umbilical Cord Blood MSC Complete Medium with $10 \% \mathrm{FBS}$ at a density of $1.5 \times 10^{4}$ cells $/ \mathrm{cm}^{2}$ in a 6 -well tissue culture plate that had been pre-coated with $0.1 \%$ gelatin solution. After $24 \mathrm{~h}$, the cells were serum-deprived for 2 days in the pretreatment medium. Then, differentiation was induced by treating miMSCs with hepatocyte differentiation media for 7 days. During the 7 days, the differentiation medium was refreshed every 2 days. Finally, cells were cultured with hepatocyte maturation medium for total 14 days to induce maturation and the maturation medium was refreshed every 2 days. Cells were placed at $37^{\circ} \mathrm{C}$ in a humidified atmosphere containing $5 \% \mathrm{CO}_{2}$ during incubation and culture. Images of treatment, differentiation and maturation were captured at the end of each step with a fluorescence microscope (Olympus Corporation, Tokyo, Japan) at magnification, x200.

Immunofluorescence. miMSCs were fixed with $4 \%$ paraformaldehyde for $10 \mathrm{~min}$. Following permeabilization with $0.2 \%$ Triton $\mathrm{X}-100$ for $8 \mathrm{~min}$, the cells were blocked with $5 \%$ FBS for $10 \mathrm{~min}$ and incubated sequentially for $90 \mathrm{~min}$ with primary antibody (mouse anti-preS2 monoclonal immunoglobulin G, 1:200, cat. no. sc-516176; Santa Cruz Biotechnology Inc., Dallas, TX, USA). Then, cells were incubated with secondary antibody (Alexa Fluor 488-conjugated goat anti-mouse immunoglobulin G, 1:200, B40941; Thermo Fisher Scientific, Inc.) for $40 \mathrm{~min}$. Between each step, cells were washed with PBS three times ( $3 \mathrm{~min} /$ time) and subsequently nuclear staining was performed using 4',6-diamidino-2-phenylindole (1:10,000; Beyotime Institute of Biotechnology, Shanghai, China) for $5 \mathrm{~min}$. Cells were examined with a fluorescence microscope (Olympus Corporation) at magnification, x200. All steps were carried out at room temperature.

Animal model construction and miMSC/shRNA treatment. The present study was approved by the Institutional Animal Care and Use Committee of Jilin University (Changchun, China) and followed the national guidelines for the treatment of animals. A total of 25 female Balb/c mice (6-8 weeks old, $20 \pm 2 \mathrm{~g}$ weight) were purchased from Liaoning Changsheng Biotechnology Co., Ltd. (Liaoning, China), allowed to acclimatize for 1 week and were maintained under standard environmental conditions (at room temperature with a $12-\mathrm{h}$ light/dark cycle, humidity 50-60\%) with ad libitum access to water and rodent chow. Mice were divided into five groups (5 mice/group). In the control group, no procedure was administered. The other four groups were treated with $1 \mathrm{ml} / \mathrm{kg} \mathrm{CCl}_{4}$ in olive oil (1:9) intraperitoneally twice a week for 4 weeks. After 4 weeks, miMSC cells ( $1 \times 10^{6}$ cells/mouse) were injected into the spleen in the miMSC group and the miMSC+shRNA, while miMSC-shRNA2 groups received miMSC-shRNA

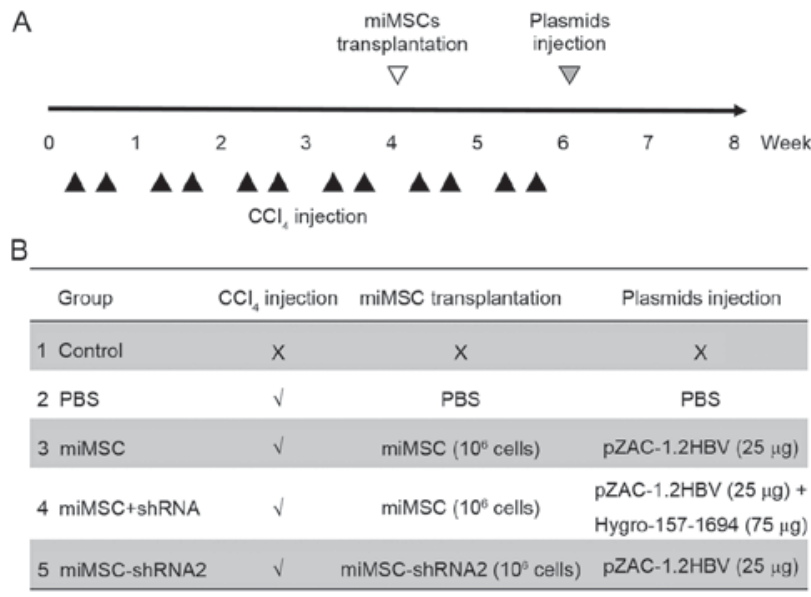

Figure 1. Experimental schedule and illustration outlining experimental groups. (A) Experimental schedule. Mice were administered with $\mathrm{CCl}_{4}$ intraperitoneally twice weekly for 4 weeks. Cells were transplanted at week $4 . \mathrm{CCl}_{4}$ was again administered twice weekly for a further 2 weeks. Plasmids were administered into the tail vein at week 6 . Subsequently, mice were sacrificed at week 8. (B) Illustration outlining the experimental groups. There were 25 mice in total, with 5 mice/group. In the control group, no procedure was administered. The other four groups were administered with $\mathrm{CCl}_{4}$. The PBS group was not transplanted with miMSCs nor administered with any plasmid, and the miMSC group was transplanted with miMSCs and injected with HBV expression plasmid. The miMSC+shRNA group was transplanted with miMSCs and administered with HBV expression plasmid together with shRNA expressing plasmid. The miMSC-shRNA2 group was transplanted with miMSC-shRNA2 and administered with HBV expression plasmid. miMSCs, mouse immortal mesenchymal stem cells; shRNA, short hairpin RNA; HBV, hepatitis B virus.

cells $\left(1 \times 10^{6}\right.$ cells/mouse) in spleen. The PBS group received an equal volume of PBS injections in the spleen. The $\mathrm{CCl}_{4}$ toxin $(1 \mathrm{ml} / \mathrm{kg})$ was administered twice a week for 2 further weeks following miMSC transplantation (12 injections in total) to induce a high selective pressure for transplanted cells to engraft and differentiate. Subsequently, mice in the control, $\mathrm{PBS}$, miMSC and miMSC+shRNA groups were injected in the tail vein with $2 \mathrm{ml}$ PBS containing $25 \mu \mathrm{g}$ HBV expression plasmid pZAC-1.2HBV plus $75 \mu \mathrm{g}$ shRNA expression plasmid, whereas the miMSC-shRNA2 group only received $25 \mu \mathrm{g}$ HBV expression plasmid Hygro-157-1694. Blood serum was collected from all groups for 10 days following plasmid injection to examine the levels of $\mathrm{HBs} \mathrm{Ag} / \mathrm{HBeAg}$. At the end of the procedure, serum samples of animals were collected for ALT/AST assays. Additionally, liver samples were taken for liver weight (LW)/body weight (BW) ratio analysis, total RNA isolation or sirius red staining. The whole animal experimental design was exhibited in Fig. 1.

RNA isolation, RT- $q$ and-semi-quantitative PCR for gene expression analysis. RNA was isolated from HepG2.2.15 cells and miMSCs or mouse liver tissues using TRIzol ${ }^{\mathrm{TM}}$ reagent (Invitrogen; Thermo Fisher Scientific, Inc.). cDNA synthesis was performed with $2 \mu \mathrm{g}$ RNA sample using a Prime Script RT Reagent kit with gDNA eraser (Takara Bio, Inc., Otsu, Japan). Then, qPCR was performed with SYBR Green PCR Super Mix (Transgene, Inc., Cambridge, MA, USA), $8 \mathrm{mM}$ each primer and 100-500 ng/ml template cDNA using a Bio-Rad CFX96 Real-Time PCR Detection system (Bio-Rad Laboratories, Inc., Hercules, CA, USA). In brief, the qPCR went through 
3 steps: Initialization $\left(98^{\circ} \mathrm{C}, 5 \mathrm{~min}\right) ; 30$ cycles of denaturation $\left(94^{\circ} \mathrm{C}, 30 \mathrm{sec}\right)$, annealing $\left(58^{\circ} \mathrm{C}, 30 \mathrm{sec}\right)$, extension $\left(72^{\circ} \mathrm{C}\right.$, $30 \mathrm{sec})$; final elongation $\left(72^{\circ} \mathrm{C}, 5 \mathrm{~min}\right)$. When the RT-PCR completed, temperature was held on $4^{\circ} \mathrm{C}$. The relative ratio and standard deviation between the normal and treated samples was calculated using the $2^{-\Delta \Delta \mathrm{Cq}}$ method (18). The expression of HBV S and HBV X genes was estimated using Bio-Rad CFX Manager 3.0 software (Bio Rad Laboratories, Inc.). $\beta$-actin was used as internal control. Semi-quantification was performed using 2X EasyTaq PCR SuperMix (Transgene, Inc.) to evaluate the gene expression levels of tyrosine transaminase (TAT), glucose-6-phosphatedehydrogenase (G-6-P), transthyretin (TTR), human albumin (ALB), cytokeratin 18 (CK18), hepatocyte nuclear factor- $3 \beta$ (HNF-3 $\beta$ ) and $\alpha$-fetoprotein (AFP). The PCR conditions were: Initialization $\left(98^{\circ} \mathrm{C}, 5 \mathrm{~min}\right) ; 25$ cycles of denaturation $\left(94^{\circ} \mathrm{C}, 30 \mathrm{sec}\right)$, annealing $\left(58^{\circ} \mathrm{C}, 30 \mathrm{sec}\right)$, extension $\left(72^{\circ} \mathrm{C}, 30 \mathrm{sec}\right)$; final elongation $\left(72^{\circ} \mathrm{C}, 5 \mathrm{~min}\right)$. When the qPCR cycle was completed the temperature was held at $4^{\circ} \mathrm{C}$. mRNA expression levels of genes were estimated using $1.5 \%$ agarose gel electrophoresis. Ethidium bromide was used for the visualization. $\beta$-actin was used as internal control. All primer sequences are listed in Table I.

Detection of $H B V$ viral antigens hepatitis $B$ surface antigen (HBsAg) and hepatitis $B$ e-antigen (HBeAg) by ELISA. Levels of HBsAg and HBeAg in the cell culture medium of HepG2.2.15 cells and sera from mice were examined using $75 \mu \mathrm{l} / \mathrm{sample}$ and commercial ELISA kits (cat. nos. KH-T-01 and KH-T-03; Shanghai Kehua Bio-Engineering Co., Ltd., Shanghai, China) according to the manufacturer's instructions. All experiments were performed in triplicate and repeated at least two times independently.

Biochemical tests. At days 0, 3, 7, 10, 13, 17 and 21 post cell-treatment with hepatocyte differentiation medium, levels of urea in the cell culture medium of miMSCs were tested using the Urea Enzymatic Assay kit (Bioo Scientific, Austin, TX, USA) according to the manufacturer's instructions. Blood samples $(\sim 0.5 \mathrm{ml})$ were taken from all experimental groups prior to sacrifice. Serum was isolated and levels of alanine aminotransferase (ALT) and aspartate aminotransferase (AST) were estimated using ALT kit (cat. no. C001-a) and AST kit (cat. no. C002-a) (all from Changchun Huili Biotech Co., Ltd., Changchun, China), respectively. HepG2 cells, which was originally misidentified as a hepatocellular carcinoma cell line but was later indicated to be derived from a hepatoblastoma (16), were used as positive controls (hepatocyte/hepatocyte-like cells) in urea production and glycogen storage assays.

Sirius red stain. Liver tissues were taken immediately, fixed in $4 \%$ paraformaldehyde (diluted in PBS) at $4^{\circ} \mathrm{C}$ overnight and then dehydrated with $20 \%$ gradient and $30 \%$ gradient sucrose-PBS solutions. Liver tissues were frozen in isopentane and kept at $-80^{\circ} \mathrm{C}$ overnight. Liver sections $(30-\mu \mathrm{m}$ thick) were obtained using a sliding microtome for following sirius red staining. Murine liver sections were picro-sirius red stained (Direct red 80; Sangon Biotech Co., Ltd., Shanghai, China) for $1 \mathrm{~h}$ at room temperature. Following staining, the sections were sealed with neutral gum. The
Table I. Primer sequences.

\begin{tabular}{|c|c|}
\hline Gene & Sequence $\left(5^{\prime}-3^{\prime}\right)$ \\
\hline$\beta$-actin & $\begin{array}{l}\text { S: TTCCTTCTTGGGTATGGAAT } \\
\text { A: GAGCAATGATCTTGATCTTC }\end{array}$ \\
\hline TAT & $\begin{array}{l}\text { S: ACCTTCAATCCCATCCGA } \\
\text { A: TCCCGACTGGATAGGTAG }\end{array}$ \\
\hline G-6-P & $\begin{array}{l}\text { S: CAGGACTGGTTCATCCTT } \\
\text { A: GTTGCTGTAGTAGTCGGT }\end{array}$ \\
\hline TTR & $\begin{array}{l}\text { S: TCTCTCAATTCTGGGGGTTG } \\
\text { A: TTTCACAGCCAACGACTCTG }\end{array}$ \\
\hline ALB & $\begin{array}{l}\text { S: TCAACTGTCAGAGCAGAGAAGC } \\
\text { A: AGACTGCCTTGTGTGGAAGACT }\end{array}$ \\
\hline CK18 & $\begin{array}{l}\text { S: TGGTACTCTCCTCAATCTGCTG } \\
\text { A: CTCTGGATTGACTGTGGAAGTG }\end{array}$ \\
\hline HNF-3 $\beta$ & $\begin{array}{l}\text { S: AGACTCCGGCGGGCACCGAG } \\
\text { A: GTGGTTGAAGGCGTAATGGT }\end{array}$ \\
\hline AFP & $\begin{array}{l}\text { S: GTGAAACAGACTTCCTGGTCCT } \\
\text { A: GCCCTACAGACCATGAAACAAG }\end{array}$ \\
\hline HBV S gene & $\begin{array}{l}\text { S: GCAGGAGGCGGATTTGC } \\
\text { A: CAAGGTAGGAGCTGGAGCATTC }\end{array}$ \\
\hline HBV X gene & $\begin{array}{l}\text { S: AGTCCAAGAGTCCTCTTATGTAAG } \\
\text { ACCTT } \\
\text { A: CCGTCTGTGCCTTCTCATCTG }\end{array}$ \\
\hline
\end{tabular}

$\mathrm{S}$, sense primer; A, antisense primer; TAT, tyrosine transaminase; G-6-P, glucose-6-phosphatedehydrogenase; TTR, transthyretin; ALB, human albumin; CK18, cytokeratin 18; HNF-3 $\beta$, hepatocyte nuclear factor $3 \beta$; AFP, $\alpha$-fetoprotein; HBV, hepatitis B virus.

red region in liver sections indicated areas that contained a high collagen level. Images were captured using a fluorescent microscope (Olympus Corporation) under natural light. Magnification, x200.

Statistical analysis. Statistical calculations were performed using GraphPad Prism 5.0 (GraphPad Software, Inc., La Jolla, CA, USA). An unpaired t-test or one-way analysis of variance followed by the Newman-Keuls test were performed to analyze the data. The results are expressed as the mean \pm standard error of the mean. $\mathrm{P}<0.05$ was considered to indicate a statistically significant difference.

\section{Results}

Construction and interference function of Lx-shRNA157, Lx-shRNA1694 and Lx-shRNA157-1694. The use of an adeno-associated virus (AAV) vector to simultaneously deliver two shRNAs targeting different HBV-related genes (157i targeting the HBV S gene and 1694i targeting the HBV X gene) has been demonstrated to result in greater antiviral effects than vectors that delivered a single shRNA in vitro and in vivo (19). In the present study, one or two shRNA expression cassettes were subcloned into a pLVX-shRNA1 vector (Fig. 2A 
A
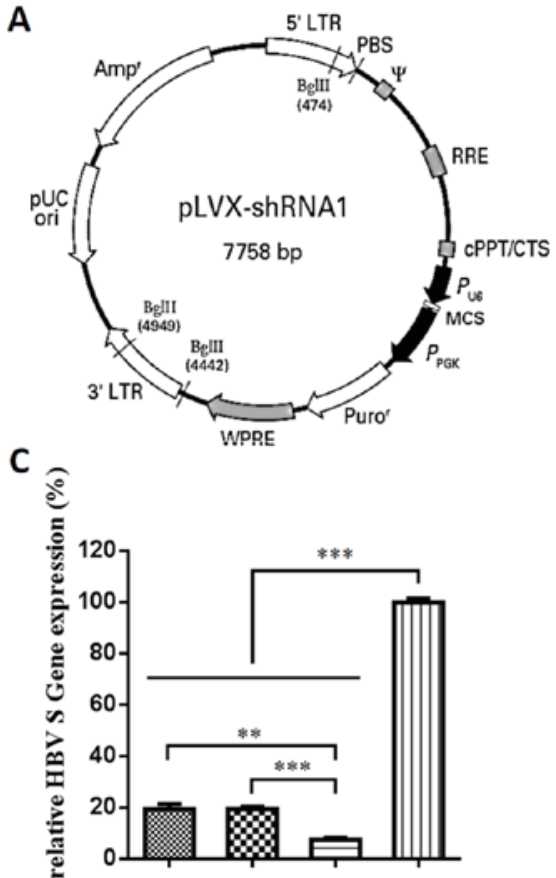

E

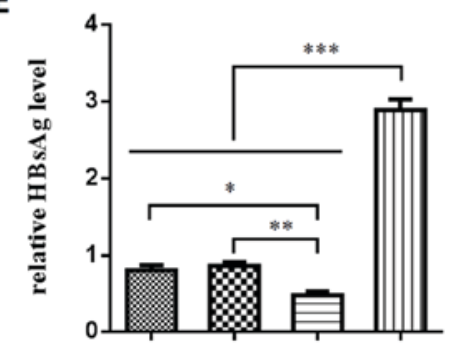

B

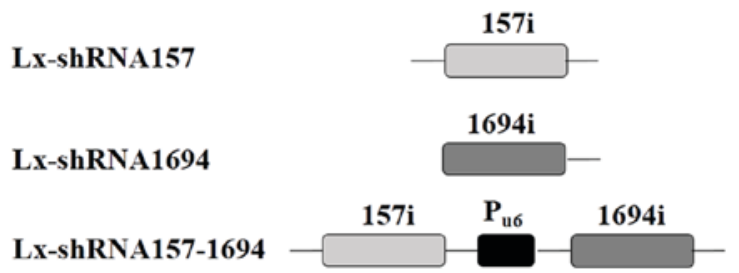

D

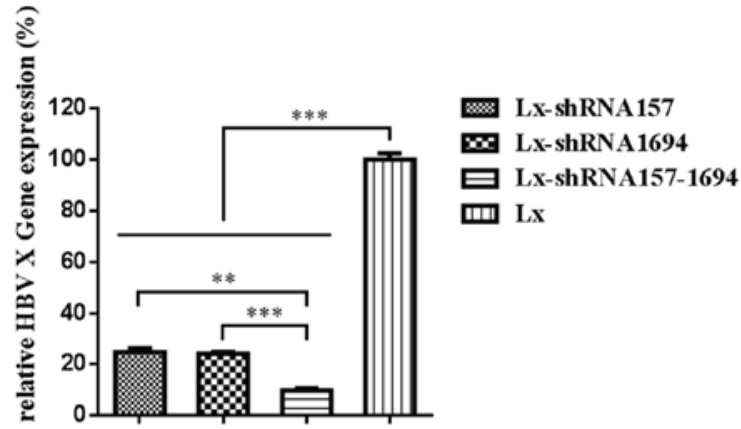

$\mathbf{F}$

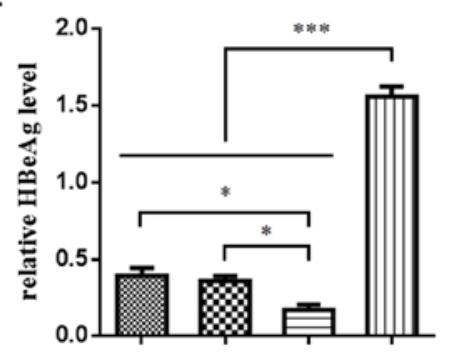

LX-shRNA157

LX Lx-shRNA1694

E Lx-shRNA157-1694

때 Lx

Figure 2. Construction and interference function of Lx-shRNA157, Lx-shRNA1694 and Lx-shRNA157-1694. (A) pLVX-shRNA1 vector map. (B) Schematic diagram of shRNA expression cassettes. RT-qPCR was used to assess the interference function of the shRNA expression plasmids against the (C) 'HBV S gene' and (D) 'HBV X gene'. ELISA was used to assess the interference function of shRNA expression plasmids against (E) HBsAg and (F) HBeAg in HepG2.2.15 cells. Lx, Lx-shRNA157 or Lx-shRNA1694, Lx-shRNA157-1694 (3 $\mu \mathrm{g})$ were transfected into HepG2.2.15 cells in 6-well plates. At 48 h post-transfection, HBV S and X gene expression levels in HepG2.2.15 cells were tested using RT-qPCR. All values are expressed as the mean + standard error of the mean ( $\mathrm{n}=3$ ). ${ }^{*} \mathrm{P}<0.05,{ }^{* *} \mathrm{P}<0.01,{ }^{* * *} \mathrm{P}<0.001$. RT-qPCR, reverse transcription-quantitative polymerase chain reaction; shRNA, short hairpin RNA; HBV, hepatitis $\mathrm{B}$ virus; HBsAg, hepatitis B surface antigen; HBeAg, hepatitis B e-antigen.

and B). In vitro anti-HBV activities of all the constructs were investigated with the aim of determining efficient vectors for anti-HBV gene therapy.

HepG2.2.15 cells were reported to derive from a hepatoblastoma (20), which was previously misidentified as a human hepatocellular carcinoma cell line. In the present study, HepG2.2.15 cells were used to test the anti-HBV activity of shRNA as HepG2.2.15 is an HBV-producing cell line. To examine anti-HBV activity, shRNA expression plasmids were transfected into HepG2.2.15 cells. From the results of RT-qPCR, HBV S mRNA expression levels in HepG2.2.15 cells transfected with Lx-shRNA157, Lx-shRNA1694 and Lx-shRNA157-1694 were 19.2, 19.3 and 7.4\%, respectively (Fig. 2C). HBV X mRNA expression levels in HepG2.2.15 cells transfected with Lx-shRNA157, Lx-shRNA1694 and Lx-shRNA157-1694 were 24.8, 24.1 and 9.8\%, respectively (Fig. 2D). Based on the ELISA results (Fig. 1E and F), the interference capacities of Lx-shRNA157, Lx-shRNA1694 and Lx-shRNA157-1694 on expression of HBV surface antigens HBsAg and HBsAg were consistent with the RT-qPCR results. Furthermore, Lx-shRNA157-1694 demonstrated significantly greater antiviral effects compared with Lx-shRNA157 or Lx-shRNA1694 at mRNA (both $\mathrm{P}<0.005)$ and protein $(\mathrm{P}<0.05$ and $\mathrm{P}<0.005$, respectively) expression levels.

Interference function of miMSCs stably expressing shRNA. Hygro-157-1694, which contains the same RNAi target as Lx-shRNA157-1694, was used to select miMSCs that were stably expressing shRNA. Two monoclones of miMSCs that stably expressed shRNA, miMSC-shRNA1 and miMSC-shRNA2, were successfully selected. pZAC-1.2HBV is an HBV genomic expression plasmid. To examine anti-HBV activity, pZAC-1.2HBV was transfected into miMSCs, miMSC-shRNA1 or miMSC-shRNA2. HBV S mRNA expression levels in miMSC-shRNA1 and miMSC-shRNA2 were 23.2 and $26.1 \%$, respectively, whereas HBV X mRNA expression levels in miMSC-shRNA1 and miMSC-shRNA2 were 24.6 and $19.7 \%$, respectively (Fig. 3A and B). HBV preS2 antigen protein expression levels in miMSC-shRNA1 and miMSC-shRNA2 were determined as 35.6 and $34.7 \%$, respectively (Fig. 3C and D). These results indicated that miMSCs stably expressing shRNA monoclones were successfully 
A

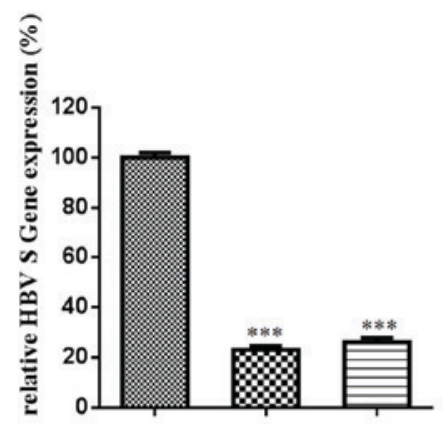

B

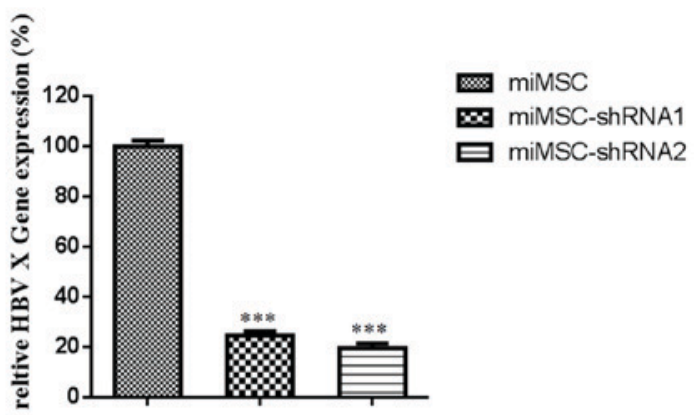

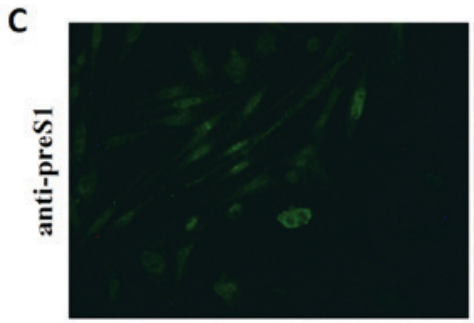
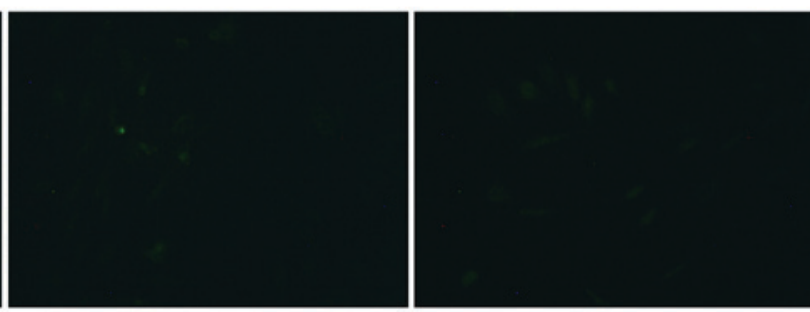

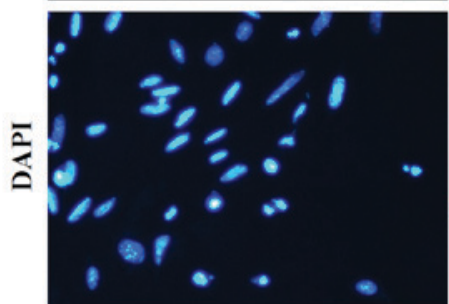

miMSC

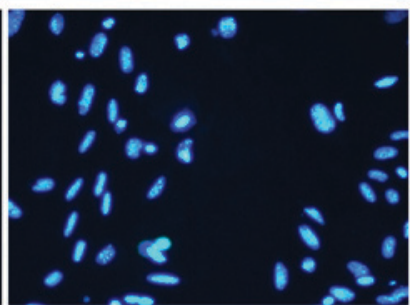

miMSC-shRNA1

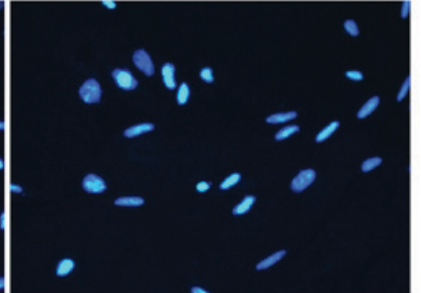

miMSC-shRNA2

D

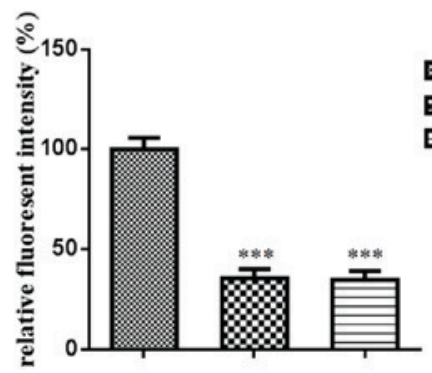

Figure 3. Interference function of miMSCs stably expressing shRNA. RT-qPCR was used to determine the effect of miMSCs stably expressing shRNA on (A) 'HBV S gene' and (B) 'HBV X gene'. (C) Immunofluorescence assay was performed to assess miMSCs stably expressing shRNA interference function on $\mathrm{HBV}$ preS2 antigen. Images were taken at magnification, x200. (D) Quantification of immunofluorescence images. RT-qPCR, reverse transcription-quantitative polymerase chain reaction. All significance indicators were obtained from comparing the miMSC-shRNA1 or miMSC-shRNA2 group with miMSC group. ${ }^{* * * *} \mathrm{P}<0.001$. shRNA, short hairpin RNA; HBV, hepatitis B virus; miMSC, mouse immortal mesenchymal stem cell; DAPI, 4',6-diamidino-2-phenylindole.

selected and both monoclones indicated similar antiviral effects at mRNA and protein expression levels.

Hepatocyte differentiation of miMSCs, miMSC-shRNA1 and miMSC-shRNA2 in vitro. To investigate whether stable-expression of shRNAs influenced the hepatogenic differentiation capability of miMSCs, hepatogenic differentiation of miMSCs, miMSC-shRNA1 and miMSC-shRNA2 was induced in vitro. The use of specific culture conditions has been reported to cause MSCs to undergo a phenotypic change, express genes which are typically expressed in hepatocytes and fulfill specific metabolic functions similar to hepatocytes (21). In the present study, phenotypic changes were recorded during hepatogenic differentiation. Prior to differentiation, cells exhibited a fibroblast-like morphology and did not markedly change during pretreatment. Following $\sim 12$ days of differentiation, cells developed a broadened flattened shape. During maturation, a polygonal cell shape was developed. Results indicated that all three cell types progressed through the same phenotypic changes as previously reported (Fig. 4A). The mRNA expression patterns of seven hepatocyte-specific markers and $\beta$-actin during the hepatogenic differentiation were investigated using semi-quantitative PCR. TAT was expressed in the three cell types between days 0-21 throughout the whole hepatogenic differentiation process, whereas G-6-P and TTR expression levels were undetectable. ALB, CK18, HNF-3 $\beta$ and AFP mRNA expression levels in the three cell types increased gradually during hepatogenic differentiation; however, AFP mRNA expression levels declined on day 21 (Fig. 4B), which is likely due to the fact that AFP is a marker of the early stage of the hepatogenic differentiation (22). Compared with Hepa1-6, ALB, CK18 and AFP mRNA expression levels in cells on day 21 were similar. However, TAT and 
A
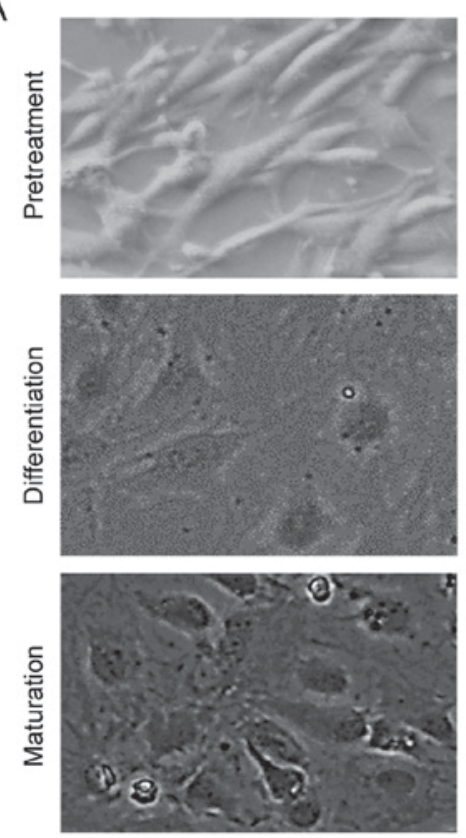

miMSC
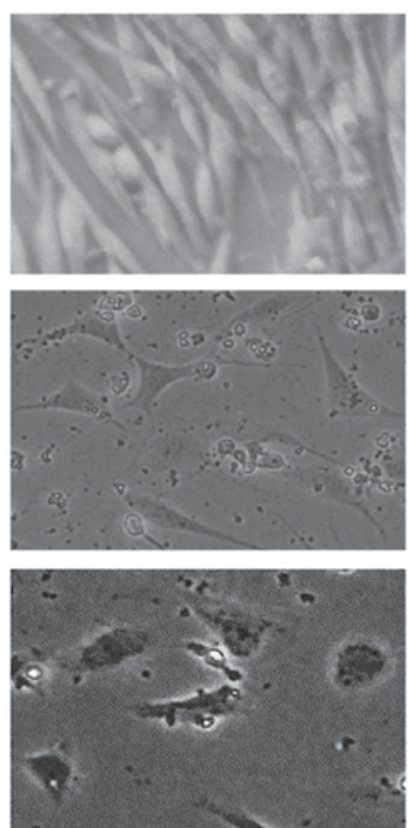

miMSC-shRNA1
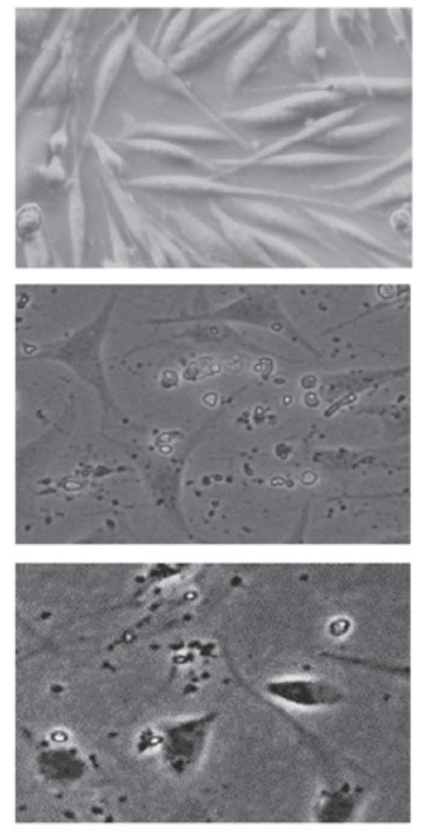

miMSC-shRNA2

B

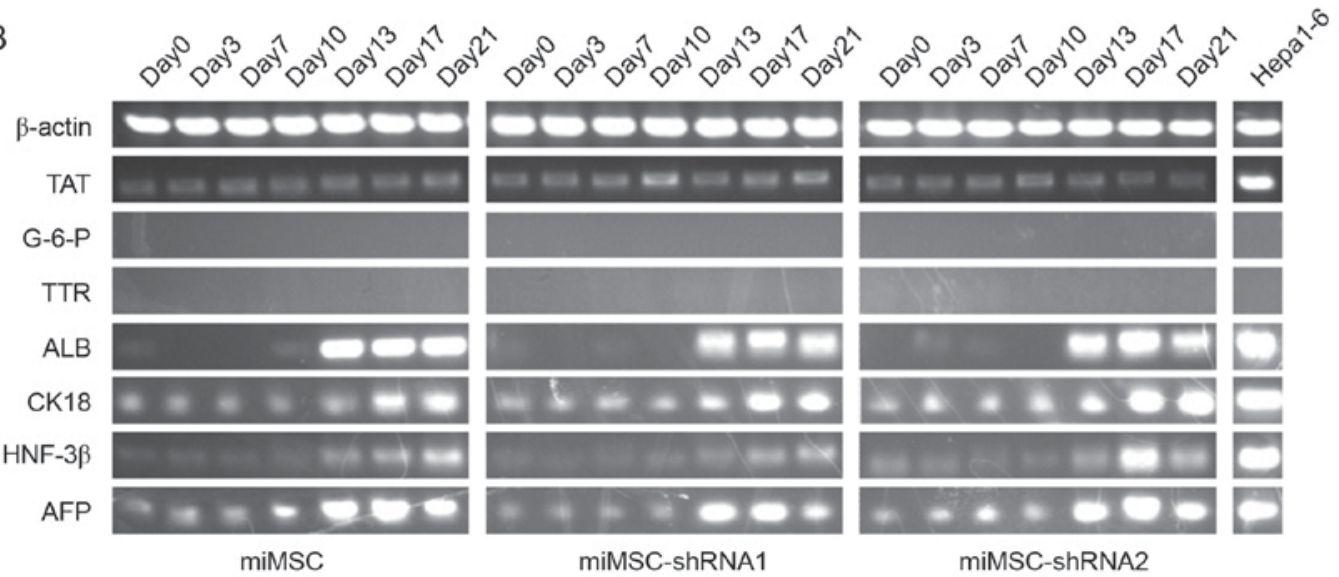

Figure 4. Analysis of hepatocyte-like cell characteristics of miMSCs, miMSC-shRNA1 and miMSC-shRNA2 during hepatogenic differentiation in vitro. (A) Morphology of differentiated hepatocytes. Images at x200 magnification were taken at the end of treatment, differentiation, maturation phase, respectively. (B) Semi-quantitative polymerase chain reaction analyses of temporal mRNA expression patterns of hepatocyte-specific markers. miMSC, mouse immortal mesenchymal stem cell. shRNA, short hairpin RNA; TAT, tyrosine transaminase; G-6-P, glucose-6-phosphatedehydrogenase; TTR, transthyretin; ALB, human albumin; CK18, cytokeratin 18; HNF-3 $\beta$, hepatocyte nuclear factor 3 $\beta$; AFP, $\alpha$-fetoprotein.

HNF-3 $\beta$ mRNA expression levels in cells on day 21 were lower compared with Hepa1-6 expression levels in all cell types. These results suggested that although miMSCs, miMSC-shRNA1 and miMSC-shRNA2 were able to differentiate into hepatocyte-like cells, there were differences between hepatocyte-like cells and hepatocytes in the mRNA expression levels of specific hepatocyte-specific markers. Furthermore, the similar expression levels of ALB mRNA in all three cell types on day 13,17 and 21 indicated that they had the similar synthetic function as hepatocytes.

Urea production and glycogen storage levels of miMSCs, miMSC-shRNA1 and miMSC-shRNA2 were also examined and indicated that these three cell types had similar urea production and glycogen storing ability (data not shown).

These results indicated that miMSCs, miMSC-shRNA1 and miMSC-shRNA2 exhibited the same ability to differentiate into hepatocyte-like cells, and our alteration had no influence on the hepatogenic differentiation capability of miMSCs.

Therapeutic effects of miMSCs combined with shRNA on HBV expression. To evaluate the therapeutic effects of miMSCs combined with shRNA on HBV expression, an in vivo mouse model was established. HBsAg and HBeAg levels in murine sera were subsequently analyzed using ELISA (Fig. 5A and B). Results demonstrated that HBsAg and HBeAg levels in the sera of mice in the control and PBS groups were almost undetectable, whereas those in the miMSC group reached a maximum level on day 2 or 1 following injection of the HBV expression plasmid injection and decreased gradually from day 3 or 2 , respectively. These findings suggested that the HBV expression plasmid was expressed successfully following injection into mice. The expression trends of $\mathrm{HBsAg}$ and HBeAg levels in the control, PBS and miMSC+shRNA 


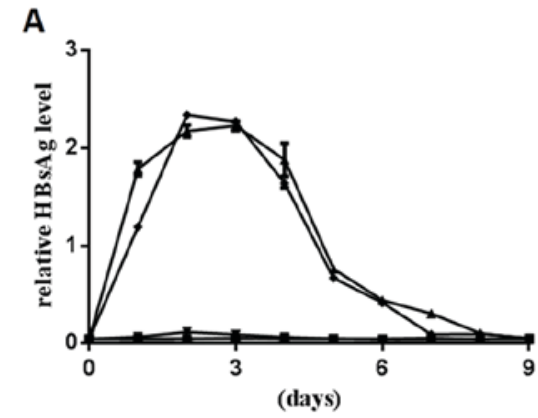

C

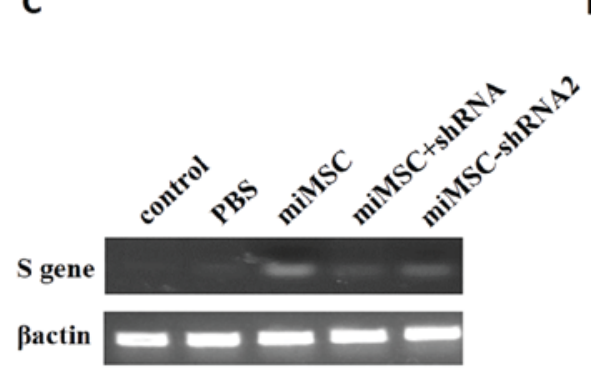

B

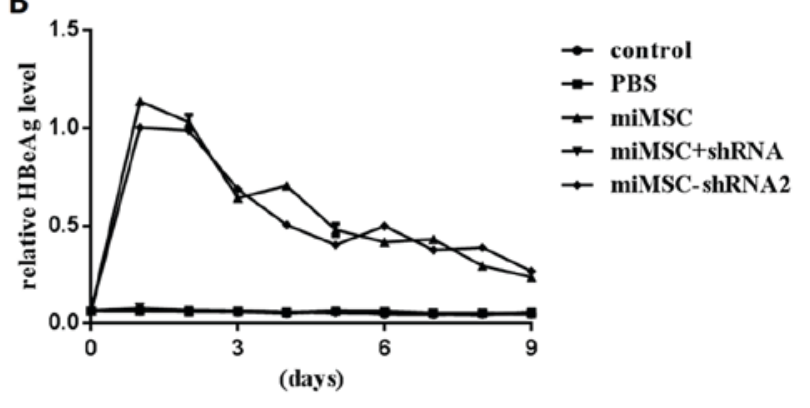

D

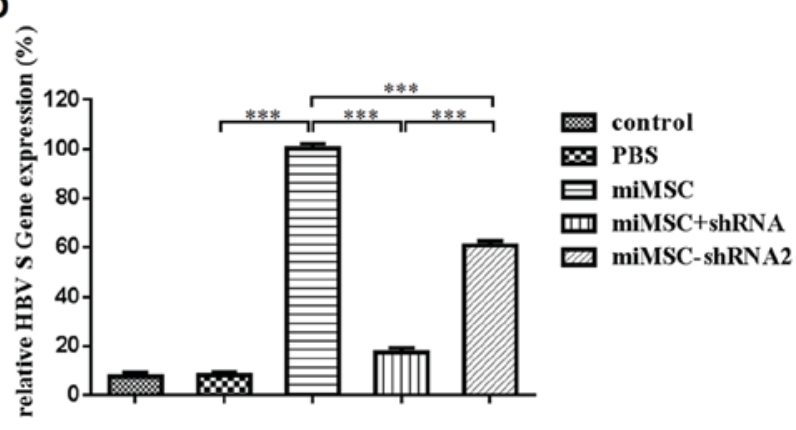

Figure 5. Reduced HBV expression in mice treated with shRNA expression plasmid or miMSC-shRNA2. ELISA assessment of shRNA expression plasmid or miMSC-shRNA2 interference function of (A) HBsAg and (B) HBeAg in murine sera. (C) Semi-quantitative PCR and (D) RT-qPCR were used to assess shRNA expression plasmid or miMSC-shRNA2 interference function of the ' $\mathrm{HBV} S$ gene'. ${ }^{* * * *} \mathrm{P}<0.001$. All values $(\mathrm{n}=3)$ are expressed as the mean + standard error of the mean. RT-qPCR, reverse transcription-quantitative polymerase chain reaction; shRNA, short hairpin RNA; HBV, hepatitis B virus; miMSCs, mouse immortal mesenchymal stem cells; HBsAg, hepatitis B surface antigen; HBeAg, hepatitis B e-antigen; PBS, phosphate-buffered saline.

groups were similar, which indicated that administration of shRNA expression plasmid through the tail vein successfully decreased the expression of HBsAg and HBeAg in sera. The expression trends of HBsAg and HBeAg levels in the miMSC and miMSC-shRNA2 groups demonstrated no significant differences, and this indicated that the transplantation of miMSCs stably expressing shRNA had nearly no influence on the expression of HBsAg and HBeAg in murine sera.

The administration of HBV expression plasmid through the tail vein induced $\mathrm{HBsAg}$ and $\mathrm{HBeAg}$ expression throughout the bodies of mice. To evaluate HBV expression in the liver, HBV S mRNA levels in murine liver tissues were tested using semi-quantitative PCR (Fig. 5C) or qPCR (Fig. 5D). The results demonstrated that HBV S mRNA expression levels in the miMSC+shRNA and miMSC-shRNA2 groups were significantly decreased compared with the miMSC group $(\mathrm{P}<0.001)$. Compared with the miMSC group, HBV S mRNA expression levels in the control,PBS, miMSC+shRNA and miMSC-shRNA2 groups were $7.7,8.3,17.5$ and $60.9 \%$, respectively.

These findings demonstrated that administration of shRNA-expressing plasmid through the tail vein successfully decreased the expression of HBsAg and HBeAg in murine sera and liver tissue compared with the miMSC group. Notably, miMSC-shRNA transplantation decreased the HBV S mRNA expression levels in murine liver; however, expression of $\mathrm{HBV}$ antigens in the sera was not suppressed.

Therapeutic effects of miMSCs combined with shRNA on liver injury. The release of ALT and AST enzymes, which are markers for liver injury (23), was measured using a commercial biochemistry analyzer (Fig. 6A and B). Results demonstrated that, following miMSC transplantation (miMSC,
miMSC+shRNA and miMSC-shRNA2 groups), ALT and AST levels in the serum decreased significantly compared with the PBS group $(\mathrm{P}<0.001)$. However, the AST levels in the serum of mice in the miMSC-shRNA2 group were significantly greater compared with that in the miMSC group $(\mathrm{P}<0.001)$. These findings revealed that our alteration of miMSCs had influenced the therapeutic effects of miMSCs on liver injury to some degree. The LW/BW ratio is also a marker for liver injury and is increased when the liver is damaged (24). The LW/BW ratio of the PBS group was significantly increased compared with the control group, indicating that the liver injury was induced by $\mathrm{CCl}_{4}(\mathrm{P}<0.001)$. In addition, results indicated that, following miMSC transplantation (miMSC, miMSC+shRNA and miMSC-shRNA2 groups), the LW/BW ratio decreased significantly compared with the PBS group ( $\mathrm{P}<0.001$; Fig. 6C). Furthermore, the LW/BW of the miMSC-shRNA2 group was significantly increased compared with the miMSC group $(\mathrm{P}<0.05)$, which was consistent with results of the AST levels in serum.

As collagen deposition is a marker for liver fibrosis (25), liver fibrosis in murine liver sections was assessed using sirius red staining in the present study (Fig. 6D). Liver sections of miMSC, miMSC+shRNA and miMSC-shRNA2 groups indicated marked reductions in fibrosis compared with that in the PBS group. Additionally, no notable fibrosis was observed in the liver sections of the control group. These results suggested that a marked reduction of liver injury had occurred in the miMSC+shRNA and miMSC-shRNA2 groups. However, the therapeutic effects of miMSC-shRNA2 transplantation against liver damage were weaker compared with miMSC transplantation and treatment with miMSC combined with shRNA, which was indicated by analyses of AST levels and LW/BW ratio. 

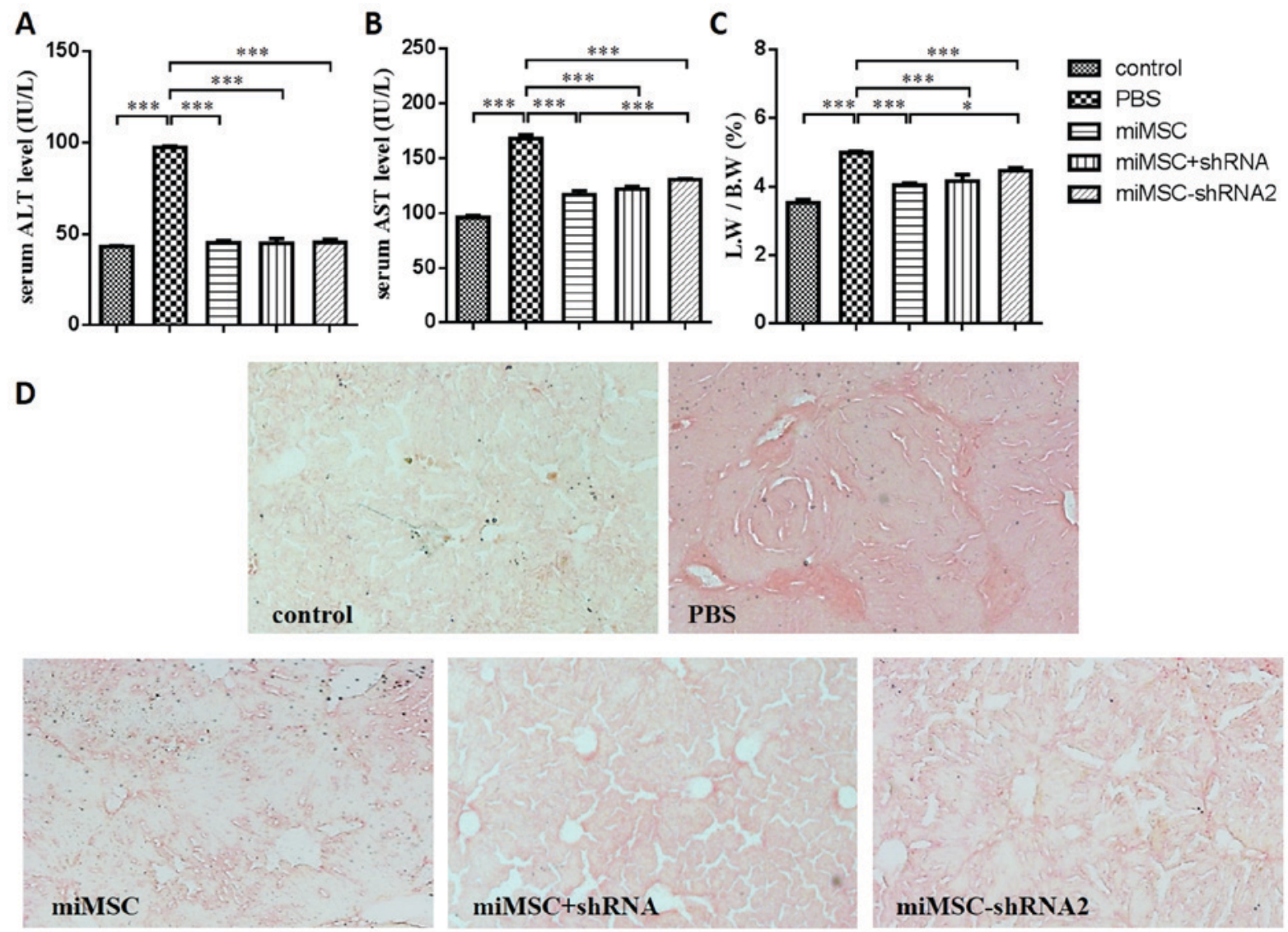

Figure 6. Reduced liver injury in mice treated with miMSCs or miMSC-shRNA2. As markers for hepatic injury, serum (A) ALT and (B) AST levels, and (C) LW/BW ratios were investigated. All values are expressed as the mean \pm standard error of the mean $(\mathrm{n}=5)$. ${ }^{*} \mathrm{P}<0.05$, ${ }^{* * * *} \mathrm{P}<0.001$. (D) Expression of collagen in liver sections was examined using sirius red staining. miMSC, mouse immortal mesenchymal stem cell. Images were taken at x200 magnification. LW/BW, liver weight/body weight; shRNA, short hairpin RNA; ALT, alanine aminotransferase; AST, aspartate aminotransferase; PBS, phosphate-buffered saline.

\section{Discussion}

HBV is responsible for $\sim 350$ million chronic infections worldwide and $>1$ million annual fatalities (26). Liver failure is a serious clinical syndrome characterized by massive necrosis of hepatocytes due to a variety of acute or chronic infections of HBV (27). Therefore, for patients with hepatitis B, suppression of $\mathrm{HBV}$ replication is not sufficient and the damaged liver function must be restored. Liver transplantation is considered the standard treatment for patients with liver failure. However, lack of tissue sources, high cost and associated complications have restricted the use of liver transplantation clinically (28). MSC transplantation therapy has become a novel and potential treatment for liver injury recently (29). Previous studies have demonstrated that the infusion of bone marrow-derived (BM)-MSCs may ameliorate liver fibrosis $(30,31)$ and reverse fulminant hepatic failure in experimental mice (32). Furthermore, infusions of autologous BM-MSCs or umbilical cord MSCs have significantly improved liver function in patients with liver cirrhosis (33) and liver failure (34).

Due to the lack of a proofreading function of its polymerase, HBV continuously undergoes rapid mutagenesis that creates multiple HBV drug-resistant variants during viral replication (35). This phenomenon affects chemotherapy outcomes in the majority of patients with chronic HBV (36). Subsequently, the requirement for alternative therapeutic approaches is urgent. Previous studies have suggested that two
shRNAs that targeted the HBV S (157i) and X (1694i) genes may be employed to avoid the phenomenon of resistance of HBV mutants to a single siRNA (19). And the dual shRNA expression vector (AAV-157i-1694i) demonstrated greater antiviral effects in vitro and in vivo compared with those vectors only expressing a single shRNA (19).

In the present study, Lx-shRNA157-1694 (shRNA expression plasmid) containing two shRNA expression cassettes was constructed to suppress HBV replication and employed with miMSC transplantation as treatment for liver injury. miMSCs were combined with shRNA in two different ways to evaluate the therapeutic effects on liver injury induced by HBV infection: By injecting miMSCs and the shRNA expression plasmid separately, or only injecting miMSCs stably expressing shRNA into the mouse model. The former therapeutic regimen successfully suppressed HBV expression in murine sera and liver tissue, whereas the latter suppressed HBV expression in liver tissue alone. Both therapeutic regimens significantly relieved liver injury. Yan et al (37) previously identified sodium taurocholate cotransporting polypeptide (NTCP) as a functional receptor for HBV. Consistent with HBV liver tropism, NTCP is primarily expressed in hepatocytes and localized to the sinusoidal plasma membrane. Therefore, in patients with chronic hepatitis B, HBV infection and replication occurs predominantly in liver tissue (38). Transplantation of miMSCs stably expressing shRNA that are able to suppress HBV expression only in liver tissue would be sufficient for clinical 
treatment. To the best of the authors' knowledge, the present study is the first to combine miMSCs with shRNA to treat liver injury and suppress HBV replication at the same time in a mouse model. Therefore, the present study provides a novel therapeutic strategy for the treatment of liver injury induced by HBV infection.

The present results revealed that the therapeutic effects of miMSC-shRNA2 transplantation on suppressing HBV expression in the liver and on relieving liver damage were weaker compared with shRNA expression plasmid injection or miMSC transplantation. This result indicated that our alteration may have influenced the migration and proliferation ability of miMSCs, such that only a small proportion of miMSC-shRNA2 had migrated to the liver and resulted in a low shRNA level in liver tissue. Incubation with recombinant HGF has been reported to increase the homing ability of MSCs towards injured liver tissue (9). Further study is required to investigate whether incubation with HGF may improve the therapeutic effects of miMSC-shRNA2 transplantation. Previous research has also indicated that double-stranded AAV vector serotype 8 (a hepatotropic AAV vector) carrying shRNA effectively reduced HBV replication and gene expression in murine liver tissue (39). miMSCs combined with an AAV8 vector carrying shRNA to treat liver injury induced by HBV infection will be used in our further study. This therapeutic regimen may improve the suppression of $\mathrm{HBV}$ expression in the liver and liver damage.

As HBV has a narrow host range, which does not include mice, a combined hydrodynamic injection mouse model (40) with a $\mathrm{CCl}_{4}$-induced liver injury mouse model (41) was constructed to simulate HBV replication and liver injury. Hydrodynamic injection of plasmids containing the HBV genome into mice has been reported to not cause liver damage (42). Therefore, liver injury in the present mouse model was caused by $\mathrm{CCl}_{4}$ injection. However, in patients with chronic hepatitis $\mathrm{B}$, liver damage is caused by CTLs during the elimination of $\mathrm{HBV}$-infected hepatocytes. Therefore, further investigation into the therapeutic effects of miMSC combined with shRNA in a more suitable animal model that can simulate liver injury caused by HBV infection is required.

In conclusion, the present study evaluated the therapeutic effects of miMSC combined with shRNAs in treating liver injury induced by $\mathrm{HBV}$ in a mouse model. The in vitro and in vivo results support the therapeutic strategy using a combination of miMSC and shRNAs and this has potential as a future therapy for the treatment of liver injury induced by $\mathrm{HBV}$ injection.

\section{Acknowledgements}

The authors would like to thank the China-Japan Union Hospital of Jilin University (Changchun, China) for providing miMSCs. The present study was supported by the National Natural Science Foundation of China (grant nos. 81472816 and 81673002) and the Science and Technology Development Plan of Jilin Province (grant nos. 20160101240JC and 20160519018JH). The authors also would like to thank Miss Phuong Thi Sarkis (sarkis-science-editing.com) for editorial support in the preparation of this study.

\section{References}

1. Lin GG, Zhang K and Li JM: Application of CRISPR/Cas9 Technology to HBV. Int J Mol Sci 16: 26077-26086, 2015.

2. Hassan MM, Li D, El-Deeb AS, Wolff RA, Bondy ML, Davila M and Abbruzzese JL: Association between hepatitis B virus and pancreatic cancer. J Clin Oncol 26: 4557-4562, 2008.

3. Suhail M, Abdel-Hafiz H, Ali A, Fatima K, Damanhouri GA, Azhar E, Chaudhary AG and Qadri I: Potential mechanisms of hepatitis B virus induced liver injury. World J Gastroentero 20: 12462-12472, 2014.

4. Guidotti LG and Chisari FV: Immunobiology and pathogenesis of viral hepatitis. Annu Rev Pathol 1: 23-61, 2006.

5. Stein LL and Loomba R: Drug targets in hepatitis B virus infection. Infect Disord Drug Targets 9: 105-116, 2009.

6. Kayaaslan B and Guner R: Adverse effects of oral antiviral therapy in chronic hepatitis B. World J Hepatol 9: 227-241, 2017.

7. Yu HB, Liu EQ, Lu SM and Zhao SH: Treatment with peginterferon versus interferon in Chinese patients with hepatitis B. Biomed Pharmacother 64: 559-564, 2010.

8. Nasir GA, Mohsin S, Khan M, Shams S, Ali G, Khan SN and Riazuddin S: Mesenchymal stem cells and Interleukin-6 attenuate liver fibrosis in mice. J Transl Med 11: 78, 2013.

9. Liu J, Pan G, Liang T and Huang P: HGF/c-Met signaling mediated mesenchymal stem cell-induced liver recovery in intestinal ischemia reperfusion model. Int J Med Sci 11: 626-633, 2014.

10. Le Blanc K and Ringdén O: Immunobiology of human mesenchymal stem cells and future use in hematopoietic stem cell transplantation. Biol Blood Marrow Transplant 11: 321-334, 2005.

11. Parekkadan B, van Poll D, Megeed Z, Kobayashi N, Tilles AW, Berthiaume $F$ and Yarmush ML: Immunomodulation of activated hepatic stellate cells by mesenchymal stem cells. Biochem Biophys Res Commun 363: 247-252, 2007.

12. Seo KW, Sohn SY, Bhang DH, Nam MJ, Lee HW and Youn HY: Therapeutic effects of hepatocyte growth factor-overexpressing human umbilical cord blood-derived mesenchymal stem cells on liver fibrosis in rats. Cell Biol Int 38: 106-116, 2014.

13. Paddison PJ, Caudy AA, Bernstein E, Hannon GJ and Conklin DS: Short hairpin RNAs (shRNAs) induce sequence-specific silencing in mammalian cells. Gene Dev 16: 948-958, 2002.

14. Sun DX, Rösler C, Kidd-Ljunggren K and Nassal M: Quantitative assessment of the antiviral potencies of 21 shRNA vectors targeting conserved, including structured, hepatitis B virus sites. J Hepatol 52: 817-826, 2010.

15. Beck J and Nassal M: Hepatitis B virus replication. World J Gastroentero 13: 48-64, 2007.

16. Wooddell CI, Yuen MF, Chan HL, Gish RG, Locarnini SA, Chavez D, Ferrari C, Given BD, Hamilton J, Kanner SB, et al: RNAi-based treatment of chronically infected patients and chimpanzees reveals that integrated hepatitis B virus DNA is a source of HBsAg. Sci Transl Med 9: eaan0241, 2017.

17. Marimani M, Hean J, Bloom K, Ely A and Arbuthnot P: Recent advances in developing nucleic acid-based HBV therapy. Future Microbiol 8: 1489-1504, 2013.

18. Livak KJ and Schmittgen TD: Analysis of relative gene expression data using real-time quantitative PCR and the 2(-Delta Delta C(T)) method. Methods 25: 402-408, 2001.

19. Li Z, He ML, Yao H, Dong QM, Chen YC, Chan CY, Zheng BJ, Yuen KY, Peng Y, Sun Q, et al: Inhibition of HBV replication and gene expression in vitro and in vivo with a single $A A V$ vector delivering two shRNA molecules. BMB Rep 42: 59-64, 2009.

20. Zhao R, Wang TZ, Kong D, Zhang L, Meng HX, Jiang Y, Wu YQ, Yu ZX and Jin XM: HHepatoma cell line HepG2.2.15 demonstrates distinct biological features compared with parental HepG2. World J Gastroentero 17: 1152-1159, 2011.

21. Meier RP, Müller YD, Morel P, Gonelle-Gispert C and Bühler LH: Transplantation of mesenchymal stem cells for the treatment of liver diseases, is there enough evidence? Stem Cell Res 11: 1348-1364, 2013.

22. Sarvandi SS, Joghataei MT, Parivar K, Khosravi M, Sarveazad A and Sanadgol N: In vitro differentiation of rat mesenchymal stem cells to hepatocyte lineage. Iran J Basic Med Sci 18: 89-97, 2015.

23. Qu M, Yuan X, Liu D, Ma Y, Zhu J, Cui J, Yu M, Li C and Guo D: Bone marrow-derived mesenchymal stem cells attenuate immune-mediated liver injury and compromise virus control during acute hepatitis B virus infection in mice. Stem Cells Dev 26: 818-827, 2017. 
24. Saat TC, van den Engel S, Bijman-Lachger W, Korevaar SS, Hoogduijn MJ, IJzermans JN and de Bruin RW: Fate and effect of intravenously infused mesenchymal stem cells in a mouse model of hepatic ischemia reperfusion injury and resection. Stem Cells Int 2016: 5761487, 2016.

25. Xie SR, An JY, Zheng LB, Huo XX, Guo J, Shih D and Zhang XL: Effects and mechanism of adenovirus-mediated phosphatase and tension homologue deleted on chromosome ten gene on collagen deposition in rat liver fibrosis. World J Gastroentero 23: 5904-5912, 2017.

26. Oh IS and Park SH: Immune-mediated liver injury in hepatitis B virus infection. Immune Netw 15: 191-198, 2015.

27. Shi M, Zhang Z, Xu R, Lin H, Fu J, Zou Z, Zhang A, Shi J, Chen L, Lv S, et al: Human mesenchymal stem cell transfusion is safe and improves liver function in acute-on-chronic liver failure patients. Stem Cell Transl Med 1: 725-731, 2012.

28. Pamecha V, Kumar S and Bharathy KG: Liver transplantation in acute on chronic liver failure: Challenges and an algorithm for patient selection and management. Hepatol Int 9: 534-542, 2015.

29. Lin BL, Chen JF, Qiu WH, Wang KW, Xie DY, Chen XY, Liu QL, Peng L, Li JG, Mei YY, et al: Allogeneic bone marrow-derived mesenchymal stromal cells for hepatitis B virus-related acute-on-chronic liver failure: A randomized controlled trial. Hepatology 66: 209-219, 2017.

30. Rabani V, Shahsavani M, Gharavi M, Piryaei A, Azhdari Z and Baharvand $\mathrm{H}$ : Mesenchymal stem cell infusion therapy in a carbon tetrachloride-induced liver fibrosis model affects matrix metalloproteinase expression. Cell Biol Int 34: 601-605, 2010.

31. Chang YJ, Liu JW, Lin PC, Sun LY, Peng CW, Luo GH, Chen TM, Lee RP, Lin SZ, Harn HJ and Chiou TW: Mesenchymal stem cells facilitate recovery from chemically induced liver damage and decrease liver fibrosis. Life Sci 85: 517-525, 2009.

32. van Poll D, Parekkadan B, Cho CH, Berthiaume F, Nahmias Y, Tilles AW and Yarmush ML: Mesenchymal stem cell-derived molecules directly modulate hepatocellular death and regeneration in vitro and in vivo. Hepatology 47: 1634-1643, 2008.

33. Terai S, Ishikawa T, Omori K, Aoyama K, Marumoto Y, Urata Y, Yokoyama Y, Uchida K, Yamasaki T, Fujii Y, et al: Improved liver function in patients with liver cirrhosis after autologous bone marrow cell infusion therapy. Stem Cells 24: 2292-2298, 2006.
34. Peng L, Xie DY, Lin BL, Liu J, Zhu HP, Xie C, Zheng YB and Gao ZL: Autologous bone marrow mesenchymal stem cell transplantation in liver failure patients caused by hepatitis B: Short-term and long-term outcomes. Hepatology 54: 820-828, 2011.

35. Buti M, Rodriguez-Frias F, Jardi R and Esteban R: Hepatitis B virus genome variability and disease progression: The impact of pre-core mutants and HBV genotypes. J Clin Virol 34 (Suppl 1): S79-S82, 2005

36. Tillmann HL: Antiviral therapy and resistance with hepatitis B virus infection. World J Gastroentero 13: 125-140, 2007.

37. Yan H, Zhong G, Xu G, He W, Jing Z, Gao Z, Huang Y, Qi Y, Peng B, Wang $\mathrm{H}$, et al: Sodium taurocholate cotransporting polypeptide is a functional receptor for human hepatitis B and D virus. Elife 1: e00049, 2012.

38. Schulze A, Schieck A, Ni Y, Mier W and Urban S: Fine mapping of pre-S sequence requirements for hepatitis B virus large envelope protein-mediated receptor interaction. J Virol 84: 1989-2000, 2010.

39. Chen CC, Sun CP, Ma HI, Fang CC, Wu PY, Xiao X and Tao MH: Comparative study of anti-hepatitis B virus RNA interference by double-stranded adeno-associated virus serotypes 7,8 , and 9 . Mol Ther 17: 352-359, 2009.

40. Yang PL, Althage A, Chung J and Chisari FV: Hydrodynamic injection of viral DNA: A mouse model of acute hepatitis B virus infection. P Natl Acad Sci USA 99: 13825-13830, 2002.

41. Higashiyama R, Inagaki Y, Hong YY, Kushida M, Nakao S, Niioka M, Watanabe T, Okano H, Matsuzaki Y, Shiota G and Okazaki I: Bone marrow-derived cells express matrix metalloproteinases and contribute to regression of liver fibrosis in mice. Hepatology 45: 213-222, 2007.

42. Huang LR, Wu HL, Chen PJ and Chen DS: An immunocompetent mouse model for the tolerance of human chronic hepatitis B virus infection. P Natl Acad Sci USA 103: 17862-17867, 2006. International (CC BY-NC-ND 4.0) License. 